\title{
pp60c-src and related tyrosine kinases: a role in the assembly and reorganization of matrix adhesions
}

\author{
Tova Volberg ${ }^{1}$, Lewis Romer ${ }^{2, *}$, Eli Zamir ${ }^{1}$ and Benjamin Geiger ${ }^{1, \ddagger}$ \\ ${ }^{1}$ Department of Molecular Cell Biology, Weizmann Institute of Science, Rehovot 76100, Israel \\ 2Departments of Pediatrics, Cell Biology and Anatomy, and Anesthesiology, University of North Carolina at Chapel Hill, NC 27599-7220, USA \\ *Present address: Departments of Anesthesiology and Cell Biology, Johns Hopkins University, Blalock 904, Baltimore, MD 21215-4904, USA \\ FAuthor for correspondence (e-mail: benny.geiger@weizmann.ac.il) \\ Accepted 20 March 2001 \\ Journal of Cell Science 114, 2279-2289 (2001) @ The Company of Biologists Ltd
}

\section{SUMMARY}

Activation of tyrosine kinases during integrin-mediated cell-matrix adhesion is involved both in the regulation of focal contact assembly and in the initiation of signaling processes at the cell-matrix adhesive interface. In order to determine the role of $\mathrm{pp}^{6} 0^{\mathrm{c}-\mathrm{src}}$ and related kinases in these processes, we have compared the dynamic reorganization of phosphotyrosine, vinculin, focal adhesion kinase and tensin in cells with altered expression of Src-family kinases. Both null cells for $\mathbf{p p 6 0} 0^{\mathrm{c}-\mathrm{src}}$ and triple knockout cells for pp60 6 -src, pp59fyn, and pp62 $^{\mathrm{c}-\mathrm{yes}}$ exhibited decreased phosphotyrosine levels in focal contacts when compared with wild-type cells. pp60 $^{\mathrm{c}-\text {-src }}$-null cells also exhibited faster assembly of cell-matrix adhesions and a more exuberant recruitment of FAK to these sites. Tensin, which normally segregates into fibrillar adhesions was localized in large focal contacts in the two mutant cell lines, suggesting

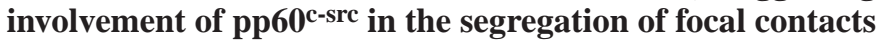
and fibrillar adhesions. Moreover, treatment of wild-type cells with tyrphostin AG1007, which inhibits both pp60 ${ }^{\text {c-src }}$ and FAK activity, induced accumulation of tensin in peripheral focal adhesions. These findings demonstrate that Src family kinases, and pp60 ${ }^{\mathrm{c}-\mathrm{src}}$ in particular, have a central role in regulating protein dynamics at cell-matrix interfaces, both during early stages of interaction and in mature focal contacts.

Key words: pp60c-src, Tensin, Focal contacts, Fibrillar adhesions, Cell-matrix adhesions, Tyrosine phosphorylation

\section{INTRODUCTION}

The attachment of cells to each other and to the surrounding extracellular matrix (ECM) plays a central role in embryonic morphogenesis and in tissue assembly. Cell-ECM adhesions occur via specific sets of membrane and cytoplasmic proteins, including specific transmembrane adhesion receptors, mainly members of the integrin superfamily, and a submembrane mesh of cytoskeleton-associated 'anchor proteins' (Hynes, 1992; Garratt and Humphries, 1995; Geiger et al., 1995; Jockusch et al., 1995; Guan, 1997). These transmembrane interactions are crucial not only for the stability of matrix adhesions but also for the assembly of the actin network and the regulation of adhesion-mediated signaling (Maher et al., 1985; Burridge et al., 1992; Volberg et al., 1992; Geiger et al., 1995; Burridge and Chrzanowska-Wodnicka, 1996; Cary et al., 1996; Frisch et al., 1996; Gilmore and Romer, 1996; Hungerford et al., 1996; Richardson and Parsons, 1996; Hanks and Polte, 1997; Zhao et al., 1998). The mechanisms responsible for these signaling events are still incompletely understood, but several kinases, along with their substrates and adapter proteins, have been detected in cell-ECM adhesions (Geiger et al., 1995; Petch et al., 1995; Burridge and Chrzanowska-Wodnicka, 1996; Yamada and Geiger, 1997). Some of these molecules directly participate in a variety of signaling events triggered by growth factors (Courtneidge et al., 1993; Matsumoto et al., 1994; Rankin and Rozengurt, 1994; Rozengurt, 1995; Auger et al., 1996; Burridge and Chrzanowska-Wodnicka, 1996). Among the most prominent of these are tyrosine-specific kinases, including focal adhesion kinase (FAK) and members of the Src family of cytoplasmic tyrosine kinases (Hanks et al., 1992; Schaller et al., 1992; Frisch et al., 1996; Ilic et al., 1997; Thomas and Brugge, 1997; Zachary, 1997; Thomas et al., 1998; Sieg et al., 1999). It has been shown that cell-ECM adhesion activates FAK kinase and stimulates its phosphorylation as well as the phosphorylation of its various substrates. FAK-associated signaling has been associated with the activation of signaling cascades that include the ERK and Jun kinase pathways, pp130 cas, and PI-3kinase (Schlaepfer et al., 1997; Schlaepfer and Hunter, 1998; Schlaepfer et al., 1998; Cary and Guan, 1999; Giancotti and Ruoslahti, 1999).

Several lines of evidence implicate $\mathrm{pp} 60^{\mathrm{c}-\mathrm{src}}$ and its homologs pp5 $59^{\mathrm{fyn}}$ and $\mathrm{pp} 62^{\mathrm{c}-\mathrm{yes}}$, in focal contact formation and modulation. The oncogenic mutant $\mathrm{pp} 60^{\mathrm{v} \text {-src }}$ has been shown to interact physically with focal contacts, extensively phosphorylate target molecules in them and affect their structure (Rohrschneider, 1980; Nigg et al., 1982; Maher et al., 1985; Hirst et al., 1986; Pasquale et al., 1986; Glenney and Zokas, 1989; Tapley et al., 1989; Volberg et al., 1991). Knockout of the Src gene was reported to suppress tyrosine phosphorylation in focal contacts (Kaplan et al., 1994; Bockholt and Burridge, 1995) and affect the adhesive properties of the cells (Kaplan et al., 1995). Conversely, increased $\mathrm{pp} 60^{\mathrm{c}-\mathrm{src}}$ or pp59fyn expression increased paxillin tyrosine phosphorylation in a FAK-dependent manner (Schaller et al., 1999). While these data suggest a role for 
pp60 6 -src in the establishment of matrix adhesions, the molecular mechanism of its effect remains unclear. Particularly intriguing is the apparent inconsistency between the role of pp60 $0^{\mathrm{c}-\mathrm{src}}$ in focal contact assembly and the destructive effect of the deregulated $\mathrm{pp} 60^{\mathrm{v}-\mathrm{src}}$ on cell-matrix adhesion.

Previous studies have indicated that focal contacts are relatively unaffected by the absence of Src family kinases (Bockholt and Burridge, 1995) except that Src-deficient cells exhibit decreased membrane ruffling (Boyce et al., 1993), smaller focal contacts with lower overall levels of tyrosine phosphorylation (Kaplan et al., 1994) and lower levels of pp130 cas phosphorylation (Bockholt and Burridge, 1995). However, the specific effects of Src family kinases on the development, morphology and composition of matrix adhesions have not been quantitatively approached.

To gain insight into the mechanism of pp60 6 -src effects on the formation and reorganization of matrix adhesions, we have analyzed the composition of these sites in cells derived from mice in which the $S r c$ gene, or the $S r c, F y n$ and Yes genes were deleted. In this study we have used quantitative microscopic analysis of matrix adhesions. We have recently applied this approach, and defined two distinct types of cell-matrix adhesions namely focal contacts and fibrillar adhesions (Zamir et al., 1999). The former, contain high levels of paxillin and vinculin, are highly tyrosine-phosphorylated and are primarily associated with $\alpha_{\mathrm{v}} \beta_{3}$ integrin. Fibrillar adhesions, however, contain $\alpha_{5} \beta_{1}$ integrin, low levels of paxillin and vinculin, and essentially no phosphotyrosine. The most prominent cytoskeletal component of fibrillar adhesions is tensin (Zamir et al., 1999). These fibrillar adhesions emerge from focal contacts and translocate in an actomyosin-dependent manner towards the cell center, forming tensin-rich linear or dot-like arrays (Zamir et al., 2000). Their formation can be blocked by immobilization of fibronectin on the tissue culture substrate (Katz et al., 2000) or by inhibition of actomyosin contractility (Zamir et al., 2000).

The data presented here demonstrate that both the development and segregation of focal contacts and fibrillar adhesions are altered in mouse fibroblasts deficient for $S r c$, or for Src, Fyn and Yes. This is manifested by an earlier onset of focal contact formation, lower levels of matrix adhesionassociated phosphotyrosine, and a marked increase in the size and intensity of tensin-containing mature adhesions. Apparent accumulation of tensin in focal adhesions was also noted in cells treated with a tyrphostin which inhibits the activity of FAK and pp60 $60^{c-s r c}$, indicating that tyrosine phosphorylation is involved in the molecular reorganization of matrix adhesions. These findings suggest a central role for Src family kinases in the regulation of the initial assembly of cell-ECM adhesions and in their subsequent molecular maturation.

\section{MATERIALS AND METHODS}

\section{Cell lines}

pp60-src null cells $\mathrm{Src}^{-1-}$, derived from mice homozygous for a disruption of the $\operatorname{Src}$ gene, wild-type mouse embryo fibroblasts, and $S_{r c}^{-l-}$ cells stably expressing the c-Src gene (wt6) were kindly provided by Pam Schwartzberg and Harold Varmus (NIH, Bethesda, MD). Fibroblasts homozygous for disruption of the Src, Fyn and Yes genes (SYF) were generously provided by $\mathrm{Dr}$ Phillipe Soriano (Fred Hutchinson Cancer Center, Seattle, WA). All cell lines were maintained in culture in Dulbecco's modified Eagle's medium (DMEM) supplemented with $10 \%$ fetal calf serum, glutamine, penicillin, streptomycin (Biological Industries, Kibbutz Beit Haemek, Israel) and $1 \mathrm{mM}$ sodium pyruvate (Sigma, St Louis, MO).

\section{Immunochemical reagents}

Primary antibodies that were used in this study include polyclonal anti-phosphotyrosine antibodies (PT40, kindly provided by Israel Pecht and Arie Licht, The Weizmann Institute) or PT-66 (purchased from Sigma Immunochemicals Ltd., Rehovot, Israel). Monoclonal antibodies against FAK, tensin and paxillin were purchased from Transduction Laboratories (Lexington, KY) and anti-vinculin (hVin1) was from Sigma. Cy3-conjugated goat anti-mouse $\mathrm{IgG} \mathrm{H}+\mathrm{L}$ (secondary antibodies for tensin staining), and Cy3-conjugated goat anti-mouse $\mathrm{F}\left(\mathrm{ab}^{\prime}\right)_{2}$ fragment were purchased from Jackson ImmunoResearch Laboratories (West Grove, PA). Alexa 488conjugated goat anti-rabbit IgG $(\mathrm{H}+\mathrm{L})$ was purchased from Molecular Probes (Eugene, OR).

\section{Immunofluorescence staining}

Cells were plated on glass coverslips precoated with $25 \mu \mathrm{g} / \mathrm{ml}$ bovine plasma fibronectin (Sigma). The cells were simultaneously permeabilized and fixed for 2 minutes with $0.5 \%$ Triton X-100 (Sigma), 3\% paraformaldehyde (Merck, Darmstadt, Germany) in phosphate-buffered saline (PBS), and then post-fixed with 3\% paraformaldehyde for additional 20 minutes. The cells were washed with PBS, incubated with primary antibodies for 40 minutes, washed again and then incubated for 40 minutes with Cy3-conjugated goat anti-mouse and Alexa 488-conjugated goat anti-rabbit antibodies. The samples were washed again with PBS, and mounted on slides using Elvanol (Mowiol 4-88, Serafon, Ashdod, Israel).

\section{Digital immunofluorescence microscopy}

Quantitative fluorescence microscopy was carried out using the DeltaVision system (Applied Precision, Issaqua, WA) attached to an inverted Zeiss Axiovert microscope using a 100X/1.3 PlanNeofluoar objective (Zeiss, Oberkochen, Germany). Images were processed using the priism software of the DeltaVision system as previously described (Zamir et al., 1999). The processing employed here included the following routines:

(1) Image filtration: original images of immunostained cells were subjected to high-pass filtration subtracting the local average intensity surrounding each matrix adhesion site.

(2) 'Spectral' presentation of fluorescence intensity: in order to visually compare fluorescence intensities, filtered images were presented using a blue-to-red linear spectrum scale.

(3) Fluorescence ratio imaging (FRI): cells were double-labeled for pairs of matrix adhesion proteins and the intensity ratio was computed per pixel as previously described (Zamir et al., 1999). The ratio images are presented in a logarithmic, spectrum scale.

(4) Segmentation and quantitation of matrix adhesions: adhesion sites in immunofluorescently labeled cells were identified and segmented using the 'water' algorithm (Zamir et al., 1999) in order to generate quantitative data on the area and average fluorescence intensity of individual adhesion sites.

In typical experiments all the adhesion sites in 10 cells (typically, 50-150 adhesion sites/cell) were examined for each time point, fluorescence label and cell type. The significance of differences between the average intensity values obtained in different cells was determined by the Wilcoxon rank-sum test with alpha $=0.001$ using the Matlab software (MathWorks, MA, USA).

\section{Immunoprecipitation and immunoblotting}

Wild-type and $\mathrm{Src}^{-1-}$ cells cultured for 24 hours, were lysed in lysis buffer (20 mM Tris- $\mathrm{HCl}$ buffer, containing 1\% Triton X-100, 150 $\mathrm{mM} \mathrm{NaCl}, 1 \mathrm{mM}$ EGTA, $1 \mathrm{mM}$ EDTA, $1 \mathrm{mM}$ sodium orthovanadate, $25 \mu \mathrm{g} / \mathrm{ml}$ leupeptin and $1 \%$ deoxycholic acid, $\mathrm{pH}$ 8.0). The lysates 


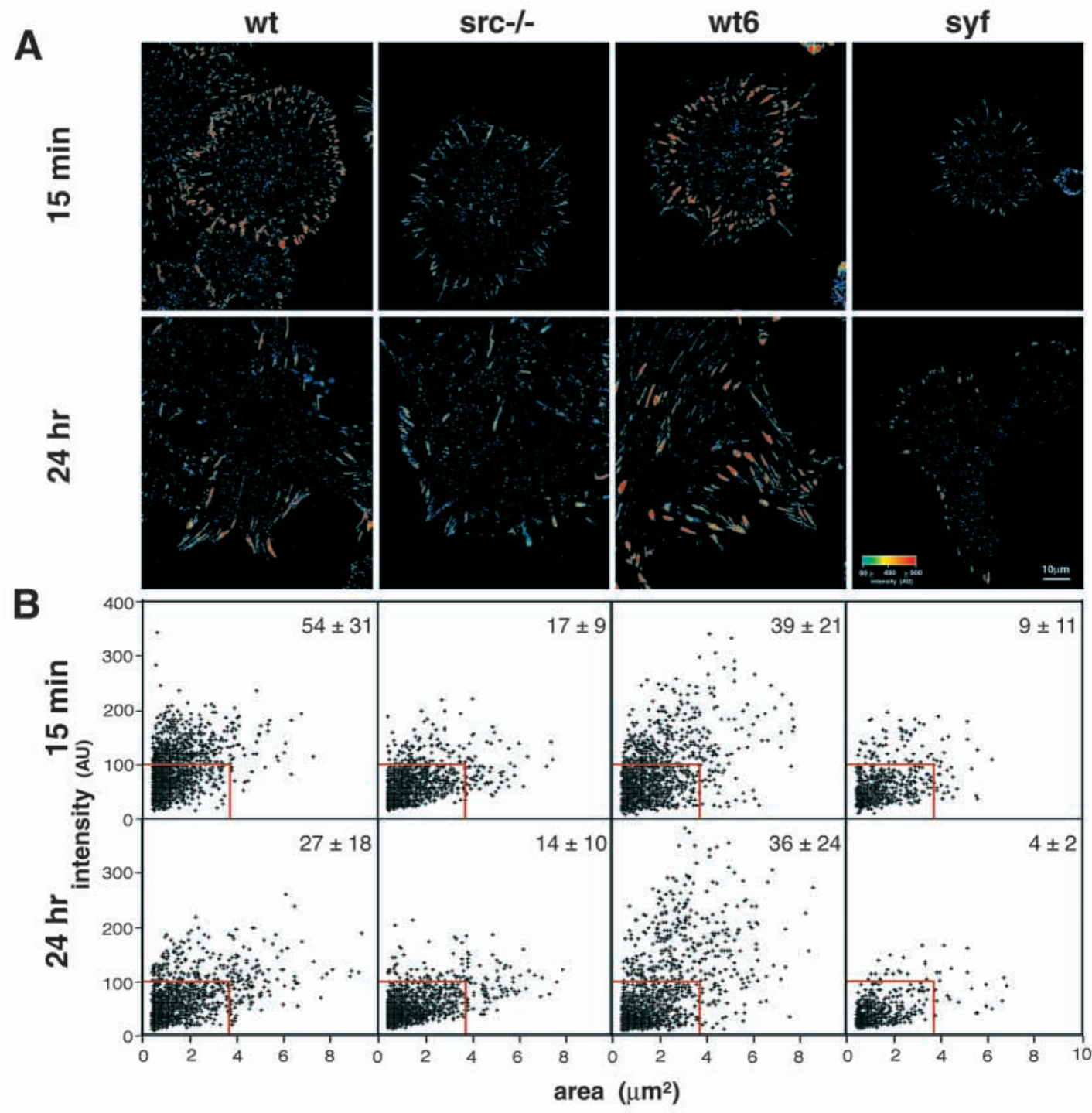

Fig. 1. Quantitative immunofluorescence labeling of wild-type, $\mathrm{Src}^{-l-}$, wt6 and SYF cells for phosphotyrosine. The cells were plated on fibronectin-coated cover glasses for 15 minutes or 24 hours, permeabilized, fixed and immunolabeled with anti-phosphotyrosine antibodies. (A) Immunofluorescence patterns of labeling, presented by a linear color look-up table. (B) Scattergrams presenting the fluorescence labeling intensity, in arbitrary units (AU), and area, in $\mu \mathrm{m}^{2}$, of phosphotyrosine-containing focal contacts in the different cell types. Each scattergram shows all the focal contacts identified in 10 representative cells, each of which contains 50-150 focal contacts. In each scattergram, the average number of relatively large and/or intensely labeled adhesions per cell is indicated. The size and intensity threshold levels were selected so that only $<10 \%$ of the adhesion sites of SYF cells were in the 'large or intense' category. Note the low labeling intensity of phosphotyrosine in $\mathrm{Src}^{-1-}$ and SYF cells compared with control wild-type and wt6 cells.

were clarified by centrifugation at $14,000 \mathrm{~g}$ for 10 minutes at $4{ }^{\circ} \mathrm{C}$ and aliquots containing equal amounts of protein (determined by Bradford assay) were incubated with antibodies to tensin for 60 minutes at $4{ }^{\circ} \mathrm{C}$. Rabbit anti mouse IgG (Jackson ImmunoResearch) bound to protein A-Sepharose was then added to the samples and incubated for additional 60 minutes at $4^{\circ} \mathrm{C}$. The beads were sedimented by brief centrifugation and washed extensively with washing buffer $(20 \mathrm{mM}$ Tris buffer, $150 \mathrm{mM} \mathrm{NaCl}, 0.1 \mathrm{mM}$ EGTA, $0.1 \mathrm{mM}$ EDTA, $1 \mathrm{mM}$ sodium orthovanadate, $25 \mu \mathrm{g} / \mathrm{ml}$ leupeptin, $0.1 \%$ Triton $\mathrm{X}-100$ and $0.1 \%$ deoxycholic acid, $\mathrm{pH} 8.0$ ). The samples were boiled in Laemmli sample buffer with $1 \mathrm{mM}$ sodium orthovanadate and subjected to 7.5\% SDS-PAGE. The proteins were then transferred to Hybond-C nitrocellulose membrane (Amersham Life Science, Buckinghamshire, UK; Towbin et al., 1992). The nitrocellulose membrane was blocked with $2 \% \mathrm{BSA}$ in buffer containing $10 \mathrm{mM}$ Tris- $\mathrm{HCl}, 150 \mathrm{mM} \mathrm{NaCl}$, and $0.05 \%$ Tween-20,
pH 7.6 (Buffer A), incubated with anti phosphotyrosine antibodies (PT-66, Sigma) at $4^{\circ} \mathrm{C}$ for 16 hours, washed extensively with Buffer $\mathrm{A}$ and then incubated with horseradish peroxidase-conjugated goat anti-mouse IgG (Amersham Life Science) for 60 minutes. The immunoreactive bands were detected by enhanced chemiluminescence (ECL, Amersham Life Science), and exposed to X-ray film. The antibodies were stripped from the Hybond-C nitrocellulose membrane by washing with $0.1 \mathrm{M}$ glycine, $\mathrm{pH} 2.9$ for 20 minutes and immunoblotted this time with tensin antibodies. The immunoreactive bands were detected again by ECL procedure. The bands were quantified by densitometry using an imaging densitometer, model GS-700 (BioRad laboratories, Hercules, CA) and analyzed by NIH Image software.

Cultured cells were washed with cold PBS, scraped off the culture dish, and extracted with Laemmli sample buffer containing $1 \mathrm{mM}$ sodium orthovanadate. The extracts were subjected to SDS- 
A

Fig. 2. (A) Phosphotyrosine-containing proteins in wild-type, $\mathrm{Src}^{-1-}$ and wt6 cells. The cells were plated on fibronectin-covered tissue culture dishes, incubated for the indicated times, then extracted in Laemmli sample buffer, subjected to 5-15\% gradient SDS-PAGE, immunoblotted and labeled with antiphosphotyrosine antibodies. The immunoreactive bands were detected using ECL. Note the progressive increase in phosphorylation of the $125 \mathrm{kDa}(\mathrm{FAK})$ and 68 $\mathrm{kDa}$ (paxillin) bands in wild-type and wt6 cells. FAK phosphorylation gradually increased in wt6 cells. In $\mathrm{Src}^{-1-}$ cells, no increase in FAK phosphorylation above basal level was detected and only a small increase in paxillin phosphorylation was observed at 24 hours. (B) Western blot analysis of tyrosine phosphorylation of tensin in $\mathrm{Src}^{-/}$and wildtype cells. The two cell types were extracted 24 hours after plating and equal amounts of protein were subjected to immunoprecipitation with tensin antibodies and immunoblotting with both tensin and phosphotyrosine antibodies. Note the comparable amounts of tensin in both cell lines and the marked decrease in tensin phosphorylation in the $\mathrm{Src}^{-/-}$cells. (C) Western blot analysis of FAK and paxillin in wild-type and $\mathrm{Src}^{-l-}$ cells. The blots reveal that the levels of FAK and paxillin in the two cell lines are essentially identical (tubulin is used as an internal control for equal protein loading).

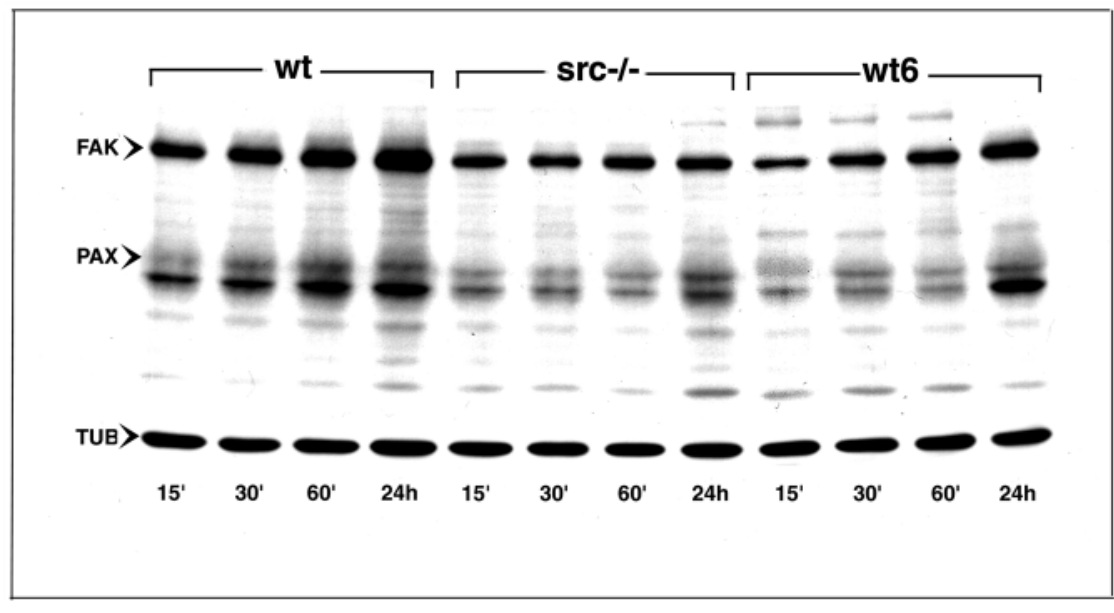

B

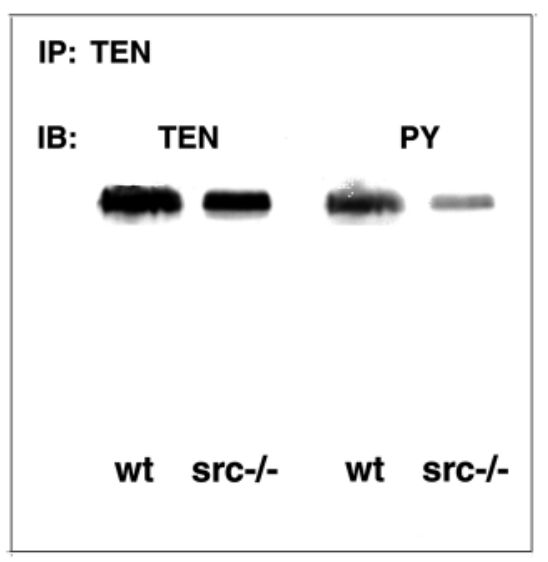

C

\section{IB: $F A K+P A X+T U B$}

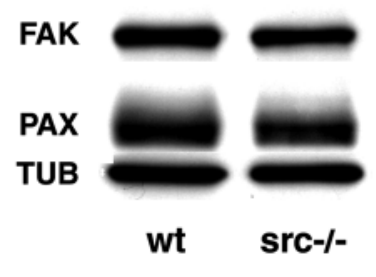

electrophoresis on 5-15\% polyacrylamide gradient gels under reducing conditions and immunoblotted with the relevant antibodies. The detection of the bands and their analysis were conducted as described above.

\section{Effect of tyrphostin AG1007 on Src kinase and FAK activity}

For Src kinase assay, microtiter plates (96-well Maxisorp, Nunc) were coated with Poly Glu-Tyr (4:1, Sigma, $0.1 \mathrm{mg} / \mathrm{ml}$ in PBS; 100 $\mu 1 /$ well). The plates were covered with Parafilm and incubated at $37^{\circ} \mathrm{C}$ for 16 hours. Excess poly Glu-Tyr was discarded and the plates were washed with TBS containing $0.2 \%$ Tween 20 (TBST) and allowed to dry at $37^{\circ} \mathrm{C}$ for $1-2$ hours. GST-Src (kindly provided by Rothem Karni and Alex Levitzki, the Hebrew University, Jerusalem, Israel; 50 ng/well) was added to the wells in the presence or absence of $50 \mu \mathrm{M}$ tyrphostin AG1007 (kindly provided by Aviv Gazit and Alex Levitzki, the Hebrew University, Jerusalem, Israel; Ohmichi et al., 1993) in kinase assay buffer $\left(20 \mathrm{mM}\right.$ Tris, $\mathrm{pH} 7.5$ and $\left.10 \mathrm{mM} \mathrm{MgCl}_{2}\right)$. The kinase reaction was started by adding $20 \mu \mathrm{M}$ ATP. The plates were incubated at $30^{\circ} \mathrm{C}$ for 20 minutes, on a shaker. The reaction was stopped by adding $200 \mathrm{mM}$ EDTA and the plate was washed with TBST and blocked with TBST containing 5\% low-fat milk. Rabbit anti-phosphotyrosine antibodies were added (100 $\mu \mathrm{l} /$ well) for 1 hour at room temperature, then washed four to six times with TBST. HRPconjugated anti rabbit IgG (Amersham Life Science) was added and incubated for another 45 minutes at room temperature, washed 5 times with TBST and once with PBS. Then $0.5 \mathrm{mg} / \mathrm{ml}$ ABTS $\left(2,2^{\prime}\right.$-Azinobis (3-Ethylbenzen-thiazoline-6-sulfonic acid, Sigma) and $0.004 \%$
$\mathrm{H}_{2} \mathrm{O}_{2}$, in citrate-phosphate buffer $(100 \mathrm{mM}$ citric acid and $200 \mathrm{mM}$ $\mathrm{Na}_{2} \mathrm{HPO}_{4}, \mathrm{pH} 4.0$ ) were added and incubated for 10 minutes and the optical density (405 nm) was read, using an Eliza Reader (ELX 800, Bio-Tek Industry).

For FAK autophosphorylation assay, pp125 FAK was immunoprecipitated from Swiss 3T3 cells extracts using antibodies to FAK (Transduction Laboratories) and protein A-sepharose. The beads were washed with lysis buffer $(20 \mathrm{mM}$ Tris- $\mathrm{HCl}$ buffer, containing $1 \%$ Triton X-100, $150 \mathrm{mM} \mathrm{NaCl}, 1 \mathrm{mM}$ EGTA, $1 \mathrm{mM}$ EDTA, $1 \mathrm{mM}$ sodium orthovanadate, $25 \mu \mathrm{g} / \mathrm{ml}$ leupeptin and $1 \%$ deoxycholic acid, $\mathrm{pH}$ 8.0) followed by TBS and then transferred to TBS containing 3 $\mathrm{mM} \mathrm{MnCl} 2$ and $10 \mathrm{mM}$ piperazine-N, $\mathrm{N}^{\prime}$-bis (2-ethanesulfonic acid) $\mathrm{pH}$ 7.4. The beads were incubated with $100 \mu \mathrm{M}$ AG1007 for $15-20$ minutes at room temperature and then incubated for additional 20 minutes with $6 \mu \mathrm{Ci}$ per sample of ${ }^{32} \mathrm{P}-\gamma \mathrm{ATP}$ (Amersham Life Science). Samples were then boiled for 3 minutes in Laemmli sample buffer containing $1 \mathrm{mM}$ sodium orthovanadate and subjected to $10 \%$ SDSPAGE. The gel was dried and the radioactive bands were detected by using a phosphoimager (BAS 1000, Fujix).

\section{RESULTS}

\section{Tyrosine phosphorylation is attenuated in pp60c-src null and SYF cells}

Since tyrosine phosphorylation appears to have a role in focal contact development (Burridge et al., 1992), we compared 
tyrosine phosphorylation in $\mathrm{Src}^{-/-}$and SYF cells with that found in wild-type cells and the wt6 clone, using quantitative microscopy and immunoblotting.

Immunofluorescence labeling of the cells following short (15 minutes) or long ( 24 hours) incubation indicated that the general morphology of tyrosine-phosphorylated focal contacts (size and subcellular location) was comparable in the various cell types, whereas the phosphorylation level of the adhesion sites in the $\mathrm{Src}^{-1-}$ and SYF cells was considerably lower than that found in wild-type or wt6 cells (Fig. 1). This can be appreciated both from the fluorescence intensity patterns (Fig. 1A) and the quantitative analysis (intensity versus area) presented in the scattergrams (Fig. 1B). Plotting immunofluorescence intensity against the area of labeled adhesion sites revealed dramatic reduction in the number of 'intense and/or large' phosphotyrosine-containing adhesion sites per cell (two- to fivefold reduction in $\mathrm{Src}^{-1-}$ and SYF cells, compared with wild-type or wt6 controls). This effect was observed following either short or long incubation.

It is noteworthy that while $\mathrm{pp} 60^{\mathrm{c}-\mathrm{src}}$ kinase apparently stimulates tyrosine phosphorylation of early and mature focal contacts, there is also a substantial pp60 ${ }^{c-s r c}$-independent phosphorylation of such sites. It is also apparent that the development of 'mature' focal contacts is not impaired by the diminished local phosphotyrosine levels seen in the $\mathrm{Src}^{-1-}$ and SYF cells.

Anti-phosphotyrosine immunoblot analysis of lysates obtained from cells following different periods of incubation after plating revealed differences in the levels of protein tyrosine phosphorylation of specific bands, between the $\mathrm{Src}^{-/}$ cells and the wild-type or wt6 controls (Fig. 2A). Specifically, phosphorylation of a $125 \mathrm{kDa}$ band, corresponding to FAK, increased progressively in the wild-type cells, while in the $\mathrm{Src}^{-/-}$cells its levels were low and did not increase significantly upon incubation. At 24 hours FAK phosphorylation in the wildtype cells and wt6 cells were 1.8- and 1.4-fold higher, respectively, than those of the Src-null cells (determined by densitometry). Phosphorylation of the $68 \mathrm{kDa}$ band, corresponding to paxillin, was also much lower in the $\mathrm{Src}^{-1-}$ cells, compared with wild type, and increased only after 24 hours of incubation. The wt6 cells exhibited intermediate levels of phosphorylation of both proteins and the levels of their phosphorylation increased upon incubation. It is noteworthy that the total levels of FAK and paxillin in wild-type and $\mathrm{SrC}^{-l-}$ cells were essentially the same (Fig. 2C). To determine the effect of pp60 6 -src knockout on tyrosine phosphorylation of tensin, extracts of wild-type and $\mathrm{Src}^{-/-}$cells were subjected to immunoprecipitation by tensin antibodies, followed by immunoblotting for phosphotyrosine. As shown in Fig. 2B, the levels of tyrosine-phosphorylated tensin (as analyzed by densitometry and normalized for changes in total tensin levels) were markedly reduced (by 62\%) in the mutant cells.

\section{Involvement of Src-family kinases in the molecular reorganization of matrix adhesions}

To determine whether the reduced phosphorylation of FAK, paxillin and tensin affected their subcellular distribution, $\mathrm{Src}^{-/-}$, SYF, wild-type and wt6 cells were immunofluorescently labeled for these proteins and examined by digital microscopy. The pattern of paxillin incorporation into matrix adhesions was not markedly affected by the absence of pp60 ${ }^{\mathrm{c}-\mathrm{src}}$, despite the reduction in its tyrosine phosphorylation (data not shown). Tensin content in adhesion sites, however, was dramatically increased in the $\mathrm{Src}^{-1-}$ and SYF cells, compared with the wildtype or wt6 cells (Fig. 3). The tensin-rich adhesion sites in the control cells consisted of scattered or clustered arrays of small dots, while in the two mutant cells, tensin was associated with large and intensely labeled adhesion sites (Fig. 3A,B). These differences were clearly manifested following both short (15 minutes) and long (24 hours) incubation.

To determine whether the observed effects are attributable to specific accumulation of tensin or to a general growth of focal contacts, the four types of cells were double labeled for tensin and vinculin and the relative labeling intensities of the two proteins compared by fluorescence ratio imaging (FRI). As shown in Fig. 4 the relative content of tensin in peripheral focal contacts of wild-type and wt6 cells was rather low (indicated by 'blue' adhesion sites), compared with the mutant cells (mainly to the $\mathrm{Src}^{-1-}$ cells), where focal contacts contained much higher relative levels of tensin, as indicated by the abundance of 'yellow' adhesion sites (Fig. 4). It is noteworthy that the spreading of the SYF cells was more limited than that of the other cell types. Vinculin levels were comparable in all cell types (data not shown). These data indicate that tensin segregation from focal contacts to fibrillar adhesions does not occur normally in the absence of pp60 ${ }^{\mathrm{c}-\mathrm{src}}$.

Immunofluorescence labeling for FAK indicated that mature FAK-labeled adhesions are quite similar in all cell types studies (Fig. 5A,B, lower panels). However, early FAK-containing adhesions, formed within 15 minutes of plating, were considerably larger and more intense in the $\mathrm{Src}^{--}$cells compared with the wild-type and wt6 controls (Fig. 5A,B, upper panels). This finding indicates that the initial recruitment of FAK to nascent adhesion sites does not depend on pp60 ${ }^{\mathrm{c}-\mathrm{src}}$ and is even suppressed by it.

\section{The effect of tyrphostin AG1007 on the exit of tensin from maturing focal contacts.}

The effects of pp60 ${ }^{\mathrm{c}-\mathrm{src}}$ on focal contact development could be attributed either to its phosphorylation activity or to its capacity to act as an 'adapter protein', recruiting different focal contact molecules via its SH2 and SH3 domains (Kaplan et al., 1995). To determine the role of tyrosine phosphorylation in the regulation of tensin segregation in maturing focal contacts, wild-type cells were treated with tyrphostin AG1007. First, we have determined the effect of AG1007 on the enzymatic activity of the two major tyrosine kinases of focal contacts,

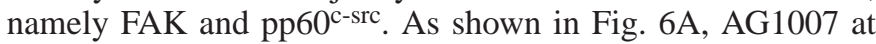
concentrations comparable with those used for treating cultured cells $(100 \mu \mathrm{M})$ partially inhibited the autophosphorylation of immunoprecipitated FAK. This tyrphostin was somewhat more effective on pp60 6 -src and reached $>80 \%$ inhibition at $50 \mu \mathrm{M}$ (Fig. 6B).

Incubation of wild-type cells with AG1007 induced a major effect on the distribution of both tensin and phosphotyrosine (Fig. 7). In the untreated fibroblasts tensin was primarily associated with numerous arrays of dots, scattered over the entire ventral surfaces of the cell (note the faintly labeled, 'blue dots' in the tensin panel). Pre-treatment with $100 \mu \mathrm{M}$ AG1007 for 2 hours, followed by replating of the cells in the presence of the drug and incubation for 5 hours, resulted in tensin accumulation in large peripheral focal contacts (note the large 


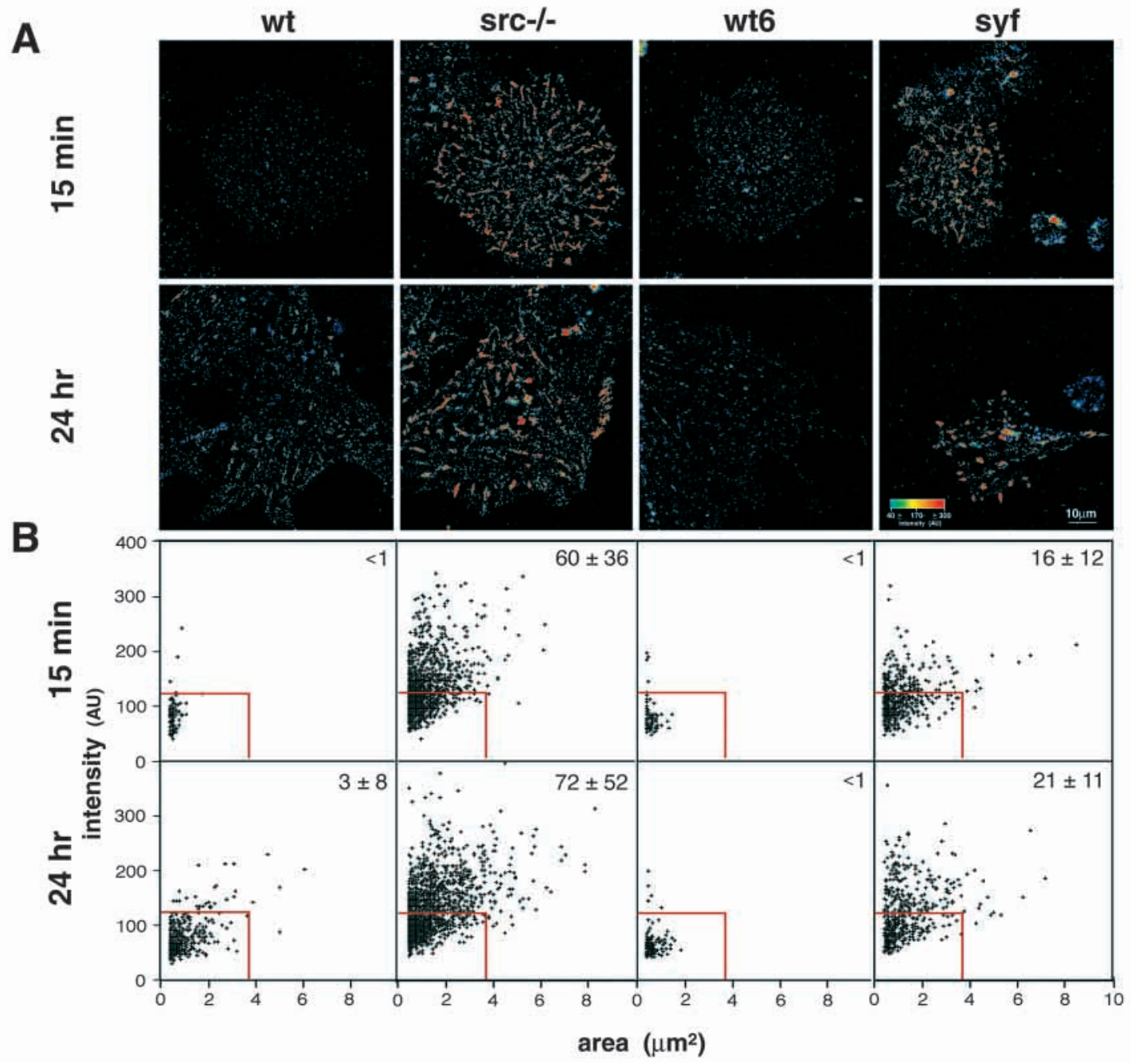

Fig. 3. Quantitative immunofluorescence labeling of wild-type, $S \mathrm{Sc}^{-/-}$, wt6 and SYF cells for tensin. The cells were plated on fibronectin-coated cover-glasses for 15 minutes or 24 hours, permeabilized, fixed and immunolabeled with anti-tensin antibodies. (A) Immunofluorescence patterns of labeling, presented by a linear color look-up table. (B) Scattergrams presenting the fluorescence labeling intensity, in arbitrary units (AU), and area, in $\mu \mathrm{m}^{2}$, of tensin-containing matrix adhesions in the different cell types. The quantitative analysis of tensin-containing matrix adhesions was performed as described for Fig. 1. The size and intensity-threshold levels were selected so that only $<5 \%$ of the adhesion sites of wild-type or wt6 cells were in the 'large or intense' category. Note the intense labeling for tensin in the focal contacts of Src ${ }^{-/}$and SYF cells, compared with control wild-type and wt6 cells.

and intensely labeled 'red' patches). These adhesion sites co-localized with phosphotyrosine. Phosphotyrosine was associated with focal contacts in both treated and non-treated cells, although the labeling intensity in the former was markedly reduced, in line with Fig. 1 above. These results indicate that inhibition of tyrosine phosphorylation by this tyrphostin induced alterations in tensin distribution and phosphotyrosine levels, similar to those observed in $\mathrm{Src}^{-/-}$and SYF cells. This is in line with the claim that Src-family kinases, and $\mathrm{pp} 60^{\mathrm{c}-\mathrm{src}}$ in particular, play a central role in the molecular reorganization of matrix adhesions via specific tyrosine kinasemediated events.

\section{DISCUSSION}

In this study we have explored the role of pp60c-src, and the related kinases pp59fyn and pp62yes in the assembly and reorganization of cell-matrix adhesions. Previous studies have provided somewhat inconclusive information on this subject. On the one hand, it has been shown that focal contacts can be formed in cells lacking pp60c-src (Kaplan et al., 1994) or even all three members of the Src family (Bockholt and Burridge, 1995). On the other hand, it has been reported that $\mathrm{Src}^{-/}$ fibroblasts display reduced adhesion and spreading when plated on fibronectin-coated surfaces. Interestingly, normal adhesion could be restored not only by pp60 $60^{\mathrm{c}-\mathrm{src}}$ but also by a mutant pp60c-src, lacking the kinase and c-terminal domains (Kaplan et al., 1995) suggesting that recruitment of other molecules mediated by the $\mathrm{SH} 2$ and $\mathrm{SH} 3$ domains of the molecule may be important for cell adhesion. It was also demonstrated that a constitutively active Src, such as pp60 ${ }^{\mathrm{v}-\mathrm{src}}$ can disrupt focal contacts and promote podosome formation (Rohrschneider, 1980; Tarone et al., 1985). While these studies suggest a central role for pp60 ${ }^{\mathrm{c}-\mathrm{src}}$ in the assembly and modulation of focal contacts, the specific molecular targets 
Fig. 4. Fluorescence ratio imaging (tensin/vinculin) showing accumulation of tensin in focal contacts of $\mathrm{Src}^{--}$and SYF cells. The cells were plated on fibronectin-coated coverglasses for 15 minutes or 24 hours, permeabilized, fixed and doubleimmunolabeled with antibodies against tensin and vinculin. The

tensin/vinculin ratios per pixel were calculated and presented by a logarithmic color look-up table, which enabled the presentation of ratio value variations spanning two orders of magnitude (from 0.1 to 10). Note the relatively low (blue) content of
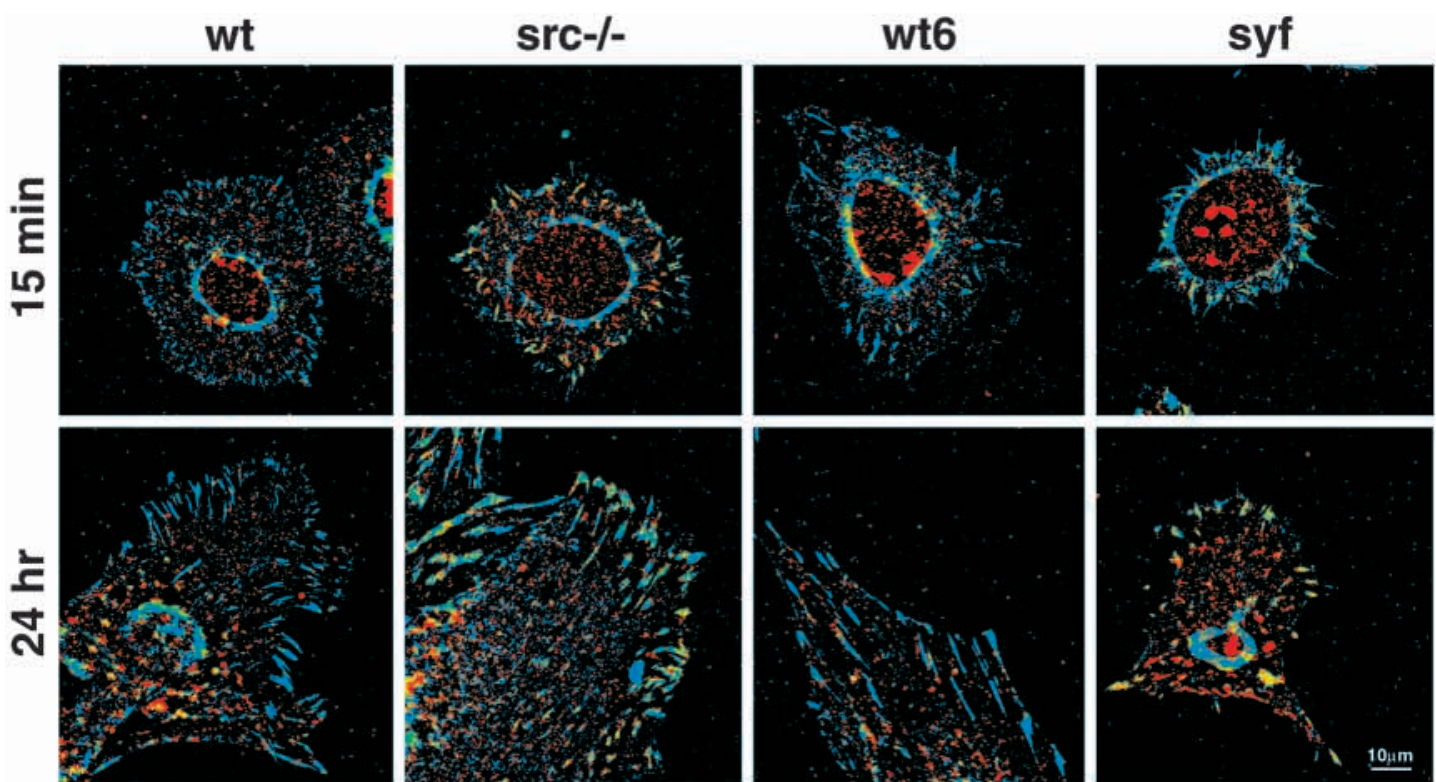

tensin in peripheral focal contacts in wild-type and wt6 cells compared with $\mathrm{Src}^{-/-}$and SYF cells, where extensive colocalization with vinculin (yellow) is apparent.

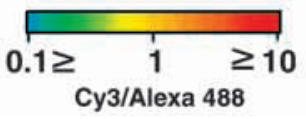

Fig. 5. Quantitative immunofluorescence labeling of wild-type, $\mathrm{SrC}^{-1-}$ and wt6 cells for FAK. The cells were plated on fibronectin-coated cover-glasses for 15 minutes or 24 hours, permeabilized, fixed and immunolabeled with anti-FAK antibodies. (A) Immunofluorescence patterns of labeling, presented by a linear color look-up table. (B) Scattergrams presenting the fluorescence labeling intensity, in arbitrary units (AU), and area, in $\mu \mathrm{m}^{2}$, of FAK-containing focal contacts in the different cell types. The quantitative analysis of FAK-containing matrix adhesions was performed as described for Fig. 1. Note the high FAK labeling in $\mathrm{Src}^{--}$cells at 15 minutes of incubation.

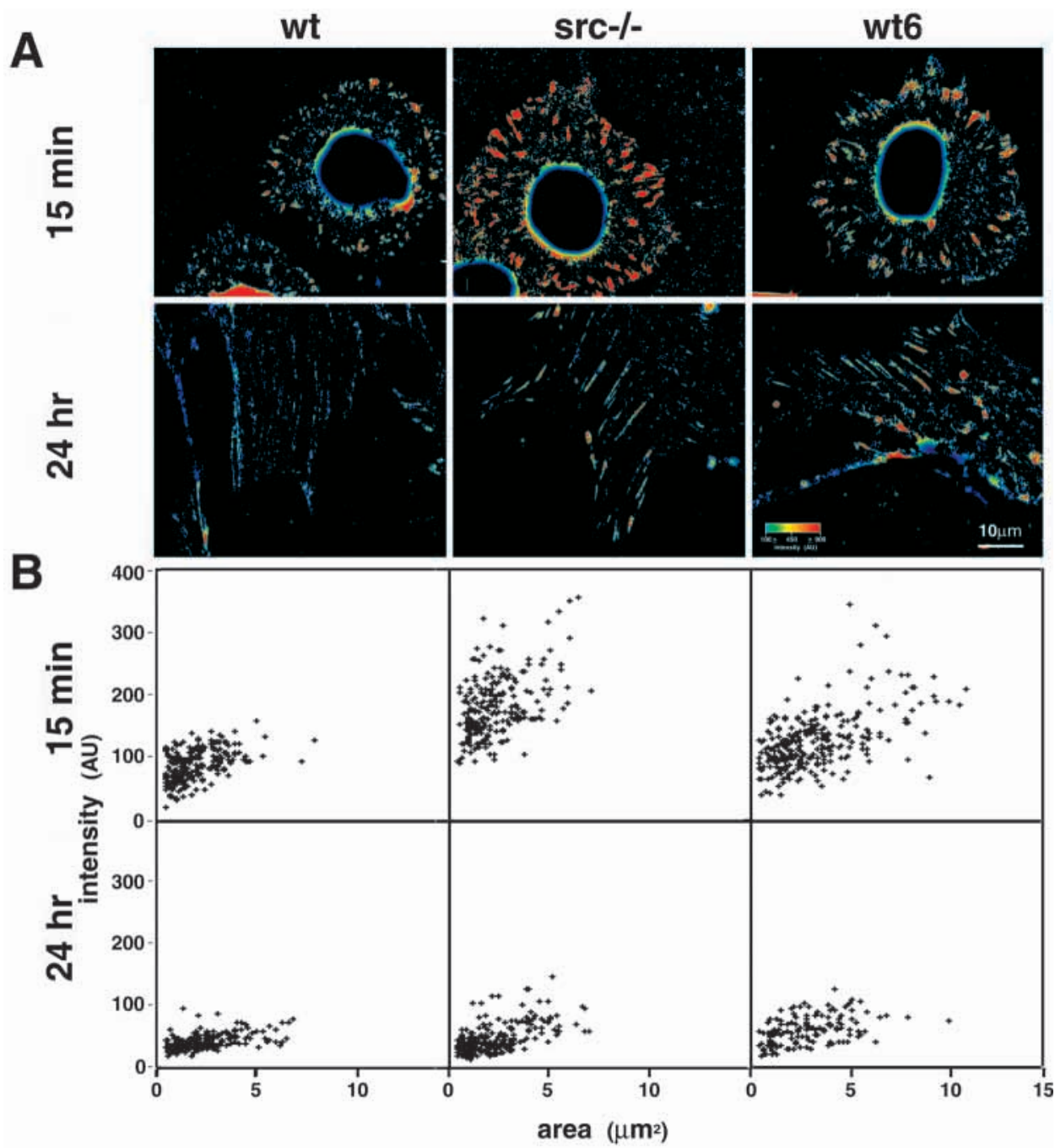


and the mechanism of action of this kinase remained unresolved.

In this study we have used quantitative microscopy to determine the levels of the different molecular components and physical properties of single adhesion sites. These quantitative microscopic assays were based on well calibrated immunofluorescence labeling, ratio analysis and computerized morphometry, essentially as previously described (Zamir et al., 1999; Katz et al., 2000; Zamir et al., 2000). In addition, we have classified the immunolabeled adhesion sites into two groups according to their size and intensity. The processing thus included two stages of image analysis:

(1) A general segmentation step, based on the application of the 'Water' algorithm (Zamir et al., 1999), revealing structures with a broad spectrum of sizes and intensities. These adhesion sites are usually dominated by small and faint structures, and thus, average values of size and intensity do not reflect changes in the stress-fiber associated focal contacts or large fibrillar adhesions.

(2) Specific counting of the number of 'large or intense' adhesions per cell. Uniform cut-off values were set so that direct comparative information can be obtained on the formation and molecular composition of large and/or intensely labeled phosphotyrosine- and tensin-containing adhesion sites in the Src-containing cells and the two mutant cell lines. As may be appreciated from Figs 1 and 3, this segmentation appears to be rather robust and small changes in the threshold levels have nearly no effect on the final conclusions.

Comparing wild-type fibroblasts to $\mathrm{Src}^{-/-}$and triple knockout cells (SYF), we detected major changes in the molecular organization of matrix adhesions. The most striking differences between Src- (or Src/Fyn/Yes-null cells) and the wild-type (or wt6) cells is the reduction in tyrosine labeling in focal contacts and the massive accumulation of tensin in these sites in the mutants. These effects appear to be primarily attributable to the absence of pp60 ${ }^{\mathrm{c}-\mathrm{src}}$, as the single and triple knockout cells display a similar phenotype, and the reintroduction of pp60 $\mathrm{c}^{\mathrm{s}-\mathrm{src}}$ into $\mathrm{Src}^{-/-}$cells (yielding the wt6 clone) fully restores the normal phenotype (e.g. focal contact phosphorylation and tensin segregation). These effects reflect changes in the molecular organization of the adhesion sites, and not merely overall change in their formation, since other components of focal contacts, like vinculin (Fig. 4) and paxillin (data not shown) did not change significantly.

An additional manifestation of Src knockout is the more exuberant recruitment of FAK into nascent focal contacts, suggesting that the initial binding of FAK is Src-independent, or even suppressed by pp60 c-src. After long incubation, FAK distribution in wild-type and mutant cells was quite similar, though its enzymatic activity was probably reduced, based on the lower levels of phosphotyrosine labeling in these sites, and the notion that phosphorylation of focal contacts is primarily attributable to FAK.

Taken together, these observations raise the possibility that pp60 6 -src-induced phosphorylation (either direct phosphorylation by $\mathrm{pp} 60^{\mathrm{c}-\mathrm{src}}$ or phosphorylation by FAK which is activated by pp60 $60^{\mathrm{c}-\mathrm{src}}$ ) is responsible for 'maturation' of focal contacts, manifested here by the exit of tensin. This hypothesis should be evaluated in light of recent information on the diversity of matrix adhesions. It has been previously shown, by photobleaching recovery assays, that focal contacts are highly dynamic structures and that their constituents (like vinculin, $\alpha$ actinin and actin) continuously exchange with a diffusible cytoplasmic pool (Kreis et al., 1985). Recently, we have discovered a novel mechanism for the dynamic reorganization of adhesion sites. It was shown (Zamir et al., 1999) that matrix adhesions are molecularly heterogeneous and consist of classical focal contacts, which are usually large, exhibit peripheral distribution and are enriched with phosphotyrosine, paxillin, vinculin and $\alpha_{\mathrm{v}} \beta_{3}$ integrin, and fibrillar adhesions, which are centrally located and are enriched with tensin and $\alpha_{5} \beta_{1}$ integrin. It was further demonstrated that fibrillar adhesions emerge from focal contacts and translocate, in an actomyosin-dependent manner, towards the cell center (Zamir et al., 2000). The dynamic properties of focal contacts may be different in motile and stationary cells (Smilenov et al., 1999) and may be involved not just in regulating adhesion and motility but also in matrix reorganization (e.g. fibrillogenesis; Pankov et al., 2000).

The results presented here (mainly the early recruitment of FAK) are consistent with the hypothesis that pp60 ${ }^{\mathrm{c}-\mathrm{src}}$ does not promote, but rather suppresses, the establishment of initial adhesions and that it plays an important role in the dynamic segregation of mature focal contacts. This is in line with experimental data showing that excessive Src-mediated tyrosine phosphorylation, caused by the constitutively active oncogenic form, pp60 ${ }^{\mathrm{v}-\mathrm{src}}$, might be detrimental to focal contacts, either by interfering with their early assembly or by unleashing their reorganization into fibrillar adhesions, leading to a dramatic loss of focal contacts and stress fibers (Rohrschneider, 1980; Volberg et al., 1991). It is interesting to note that excessive activity of pp60 $0^{\mathrm{v}-\mathrm{src}}$ is attributable to at least two factors: the insensitivity of the kinase activity to Cskmediated downregulation (Kmiecik and Shalloway, 1987; Nada et al., 1991) and to the constitutive association of the molecule with adhesion sites (Kaplan et al., 1995; Felsenfeld et al., 1999).

Further support for the notion that focal contact reorganization (e.g. segregation of focal contacts and fibrillar adhesions) depends on tyrosine phosphorylation is obtained from the accumulation of tensin in focal contacts of the triple knockout (SYF) cells and from additional experiments in which tyrosine phosphorylation in wild-type cells was suppressed by specific tyrphostins. Thus, cells treated with AG1007, which was shown to inhibit pp60 6 -src and FAK in vitro, developed a ' $\mathrm{Src}^{-/-}$phenotype'. These studies were performed in order to determine whether the effects of pp60 ${ }^{\mathrm{v}-\mathrm{src}}$ on focal contact reorganization are attributable to tyrosine phosphorylation per se, or to its capacity to act as an adapter protein, irrespective of its enzymatic activity (Kaplan et al., 1995). The data presented here favor the former possibility. It remains, however, to be determined whether $\mathrm{pp} 60^{\mathrm{v}-\mathrm{src}}$ is directly responsible for the phosphorylation events which drive focal contact reorganization or whether it exerts its effect indirectly (by activating FAK, for example).

The molecular mechanism underlying the effect of pp60 ${ }^{\mathrm{c}-\mathrm{src}}$ on focal contact reorganization is not known. Furthermore, even the full repertoire of specific molecular targets of pp60 ${ }^{\mathrm{c}-\mathrm{src}}$, the phosphorylation of which might be responsible for the phenotype described here is not clear. The difficulty in defining the precise 'molecular targets' of the pp $60^{\mathrm{c}-\mathrm{src}}$ effects on matrix adhesions is primarily attributable to the fact that many 
A

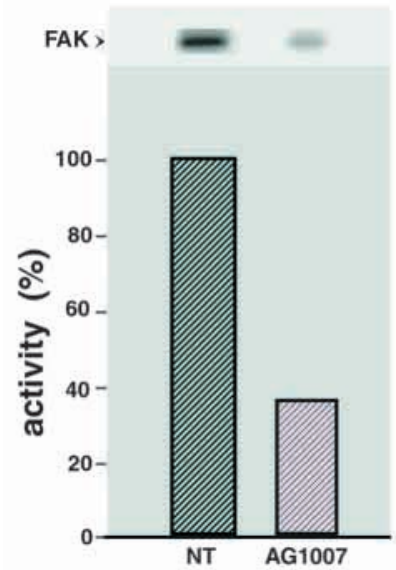

B

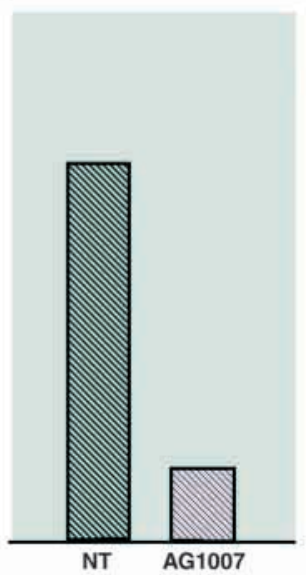

structural components of focal contacts are potential pp60 $60^{\mathrm{c}-\mathrm{src}}$ substrates. These include FAK, paxillin, tensin, talin, pp130 cas, $\beta$-integrin and P-I3K (Hirst et al., 1986; Pasquale et al., 1986; DeClue and Martin, 1987; Glenney and Zokas, 1989; Reynolds et al., 1989; Findik et al., 1990; Davis et al., 1991; Fukui and Hanafusa, 1991; Wu et al., 1991; Schaller et al., 1992, Liu et al., 1993; Sakai et al., 1994; Turner and Miller, 1994; Calalb et al., 1995; Haefner et al., 1995; Fincham and Frame, 1998; Schlaepfer and Hunter, 1998). Moreover, a variety of signaling molecules that might regulate focal contact assembly and integrinmediated signaling were shown to be tyrosine-phosphorylated by the Src kinase (i.e. Ellis et al., 1990; Nakanishi et al., 1993). For example, the Rho family of small GTPases may be one means by which Src regulates matrix adhesion assembly. Recent data (Arthur et al., 2000) indicate that integrin-mediated cell-matrix adhesion inactivates RhoA in a Src-dependent fashion via the tyrosine phosphorylation of p190RhoGAP. This mechanism is deficient in SYF-null cells (Arthur et al., 2000).

How could tyrosine phosphorylation promote focal contact reorganization? One attractive speculation that we offer is inspired by the conformational changes that

Fig. 7. Reorganization of tensin in wild-type cells After treatment with AG1007. Wild-type cells were cultured for 24 hours, treated with $100 \mu \mathrm{M}$ AG1007 for 2 hours and then trypsinized and re-plated on fibronectin-coated cover glasses in the presence of $100 \mu \mathrm{M}$ AG1007, for additional 5 hours. The cells were fixed and double immunolabeled for tensin and phosphotyrosine. The treatment induced tensin accumulation in large peripheral focal contacts (upper panel) and reduction in phosphotyrosine levels (middle panel and super-imposed image, bottom panel). Phosphotyrosine was associated with focal contacts in both treated and untreated cells.

Fig. 6. Inhibition of FAK and Src activity by AG1007. (A) pp125 FAK that was immunoprecipitated from cultured swiss $3 \mathrm{~T} 3$ cells extracts by antibodies to FAK, was equally divided to two samples. One was used as a control (NT) and the other was incubated with $100 \mu \mathrm{M}$ AG1007 for 15-20 minutes at room temperature. Both samples were incubated for additional 20 minutes with $6 \mu \mathrm{Ci}$ per sample, ${ }^{32} \mathrm{P}$ labeled $\gamma$ ATP. The samples were subjected to $10 \%$ SDS-PAGE and the radioactive bands detected using a phosphoimager. Note that FAK activity was inhibited up to $60 \%$ by AG1007. (B) GST-Src was assayed for its activity on poly Glu-Tyr ELISA assay in the absence or presence of $50 \mu \mathrm{M}$ AG1007. Note that AG1007 inhibited Src activity by $80 \%$.

occur in pp60 ${ }^{\mathrm{c}-\mathrm{src}}$ itself after phosphorylation by Csk at position Y527 (Nada et al., 1991). It has been shown that after such phosphorylation pp60 $60^{\mathrm{c}-\mathrm{src}}$ folds into an enzymatically inactive 'closed conformation', where the SH2 domain binds to the phospho-Y527. Folding of cytoskeleton-associated molecules such as ezrin or vinculin, owing to intramolecular interactions (induced by phosphorylation or other modifications) could also modulate their interactions with the cytoskeleton and affect the
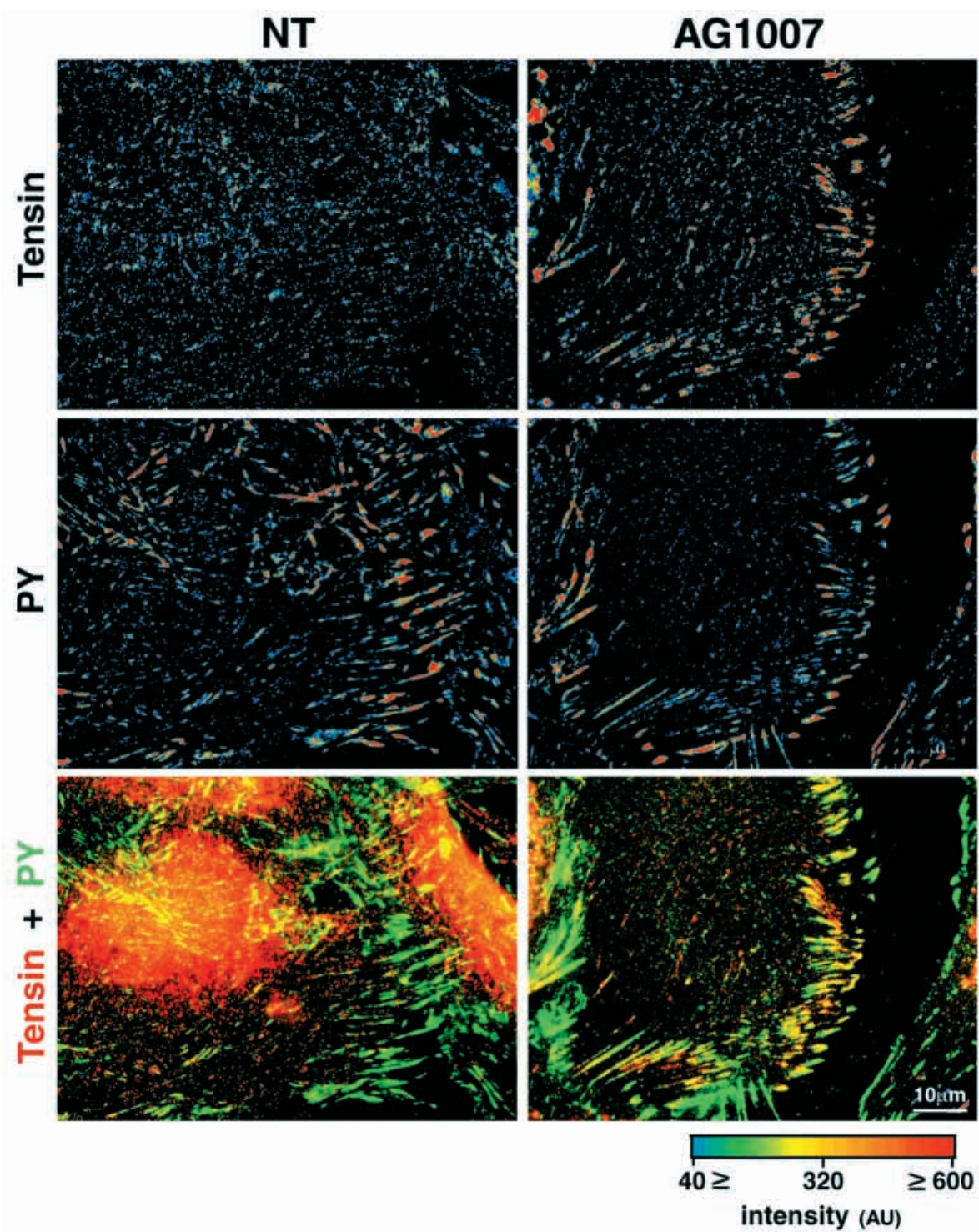
cytoskeletal networks with which they interact (Bretscher et al., 1997, Johnson and Craig, 1994; Johnson and Craig, 1995). An attractive candidate for a pp60 ${ }^{\mathrm{c}-\mathrm{src}}$ target protein whose phosphorylation might affect its cytoskeletal interactions is tensin. As previously reported (Davis et al., 1991; Bockholt and Burridge, 1993) and confirmed in this study (Fig. 2). tensin is tyrosine phosphorylated in a Src-dependent manner. Tensin also contains one $\mathrm{SH} 2$ domain and several additional binding sites for actin (Davis et al., 1991; Lo et al., 1994), vinculin, $\beta$ integrin (Lin and Lin, 1996) and PI3K (Auger et al., 1996), and was also found to associate with p130 cas (Salgia et al., 1996).

If tyrosine phosphorylation of tensin induces intramolecular interaction between the phosphorylated site and the $\mathrm{SH} 2$ domain of the molecule (analogous to the effect of Y527 phosphorylation of $\mathrm{pp} 60^{\mathrm{c}-\mathrm{src}}$ ) some of these cytoskeletal interactions may be perturbed and the molecule may be more readily mobilized away from the focal contact by the associated actomyosin system (Zamir et al., 2000). Direct attempts to test this hypothesis are currently underway.

We acknowledge with gratitude Pam Schwartzberg and Harold Varmus (NIH, Bethesda MD) for providing the wild-type, $\mathrm{Src}^{-1-}$ and wt6 cells, and for illuminating discussions. We also thank Phillipe Soriano (Fred Hutchinson Cancer Center, Seattle, WA) for providing the SYF cells and Natalie V. McLean for technical support. This study was supported by the Israel Science Foundation, the Yad Abraham Center for Cancer Diagnosis and Therapy, the Minerva Foundation, a Fogarty Senior International Fellowship to L. R. (F06TW02341), and NHLBI (HL-03299 and HL-56395). B. G. holds the Erwin Neter Chair in Cell and Tumor Biology.

\section{REFERENCES}

Arthur, W. T., Petch, L. A. and Burridge, K. (2000). Integrin engagement suppresses RhoA activity via a c-Src-dependent mechanism. Curr. Biol. 10, 719-722.

Auger, K. R., Songyang, Z., Lo, S. H., Roberts, T. M. and Chen, L. B. (1996). Platelet-derived growth factor-induced formation of tensin and phosphoinositide 3-kinase complexes. J. Biol. Chem. 271, 2345223457.

Bockholt, S. M. and Burridge, K. (1993). Cell spreading on extracellular matrix proteins induces tyrosine phosphorylation of tensin. J. Biol. Chem. 268, $14565-14567$.

Bockholt, S. M. and Burridge, K. (1995). An examination of focal adhesion formation and tyrosine phosphorylation in fibroblasts isolated from src-, fyn-, and yes- mice. Cell Adhes Commun 3, 91-100.

Boyce, B. F., Chen, H., Soriano, P. and Mundy, G. R. (1993). Histomorphometric and immunocytochemical studies of src-related osteopetrosis. Bone 14, 335-340.

Bretscher, A., Reczek, D. and Berryman, M. (1997). Ezrin: a protein requiring conformational activation to link microfilament to the plasma membrane in the assembly of cell surface structures. J. Cell Sci. 110, 30113018.

Burridge, K., Turner, C. E. and Romer, L. H. (1992). Tyrosine phosphorylation of paxillin and pp125FAK accompanies cell adhesion to extracellular matrix: a role in cytoskeletal assembly. J. Cell Biol. 119, 893903.

Burridge, K. and Chrzanowska-Wodnicka, M. (1996). Focal adhesions, contractility, and signaling. Апnи. Rev. Cell Dev. Biol. 12, 463-518.

Calalb, M. B., Polte, T. R. and Hanks, S. K. (1995). Tyrosine phosphorylation of focal adhesion kinase at sites in the catalytic domain regulates kinase activity: a role for Src family kinases. Mol. Cell. Biol. 15, 954-963.

Cary, L. A., Chang, J. F. and Guan, J. L. (1996). Stimulation of cell migration by overexpression of focal adhesion kinase and its association with Src and Fyn. J. Cell Sci. 109, 1787-1794.
Cary, L. A. and Guan, J. L. (1999). Focal adhesion kinase in integrinmediated signaling. Front. Biosci. 4, D102-D113.

Courtneidge, S. A., Fumagalli, S., Koegl, M., Superti-Furga, G. and Twamley-Stein, G. M. (1993). The Src family of protein tyrosine kinases: regulation and functions. Development 117, Suppl., 57-64.

Davis, S., Lu, M. L., Lo, S. H., Lin, S., Butler, J. A., Druker, B. J., Roberts, T. M., An, Q. and Chen, L. B. (1991). Presence of an SH2 domain in the actin-binding protein tensin. Science 252, 712-715.

DeClue, J. E. and Martin, G. S. (1987). Phosphorylation of talin at tyrosine in Rous sarcoma virus-transformed cells. Mol. Cell. Biol. 7, 371-378.

Ellis, C., Moran, M., McCormick, F. and Pawson, T. (1990). Phosphorylation of GAP and GAP-associated proteins by transforming and mitogenic tyrosine kinases. Nature 343, 377-381.

Felsenfeld, D. P., Schwartzberg, P. L., Venegas, A., Tse, R. and Sheetz, M. P. (1999). Selective regulation of integrin-cytoskeleton interactions by the tyrosine kinase Src. Nat. Cell Biol. 1, 200-206.

Fincham, V. J. and Frame, M. C. (1998). The catalytic activity of Src is dispensable for translocation to focal adhesions but controls the turnover of these structures during cell motility. EMBO J. 17, 81-92.

Findik, D., Reuter, C. and Presek, P. (1990). Platelet membrane glycoproteins IIb and IIIa are substrates of purified pp $60^{c-s r c}$ protein tyrosine kinase. FEBS Lett. 262, 1-4.

Frisch, S. M., Vuori, K., Ruoslahti, E. and Chan-Hui, P. Y. (1996). Control of adhesion-dependent cell survival by focal adhesion kinase. J. Cell Biol. 134, 793-799.

Fukui, Y. and Hanafusa, H. (1991). Requirement of phosphatidylinositol-3 kinase modification for its association with p60src. Mol. Cell Biol. 11, 19721979.

Garratt, A. N. and Humphries, M. J. (1995). Recent insights into ligand binding, activation and signalling by integrin adhesion receptors. Acta Anat. 154, 34-45.

Geiger, B., Yehuda-Levenberg, S. and Bershadsky, A. D. (1995). Molecular interactions in the submembrane plaque of cell-cell and cell-matrix adhesions. Acta Anat. 154, 46-62.

Giancotti, F. G. and Ruoslahti, E. (1999). Integrin signaling. Science 285, 1028-1032.

Gilmore, A. P. and Romer, L. H. (1996). Inhibition of focal adhesion kinase (FAK) signaling in focal adhesions decreases cell motility and proliferation. Mol. Biol. Cell 7, 1209-1224.

Glenney, J. R., Jr and Zokas, L. (1989). Novel tyrosine kinase substrates from Rous sarcoma virus-transformed cells are present in the membrane skeleton. J. Cell Biol. 108, 2401-2408.

Guan, J. L. (1997). Role of focal adhesion kinase in integrin signaling. Int. J. Biochem. Cell Biol. 29, 1085-1096.

Haefner, B., Baxter, R., Fincham, V. J., Downes, C. P. and Frame, M. C. (1995). Cooperation of Src homology domains in the regulated binding of phosphatidylinositol 3-kinase. A role for the Src homology 2 domain. $J$. Biol. Chem. 270, 7937-7943.

Hanks, S. K., Calalb, M. B., Harper, M. C. and Patel, S. K. (1992). Focal adhesion protein-tyrosine kinase phosphorylated in response to cell attachment to fibronectin. Proc. Natl. Acad. Sci. USA 89, 8487-8491.

Hanks, S. K. and Polte, T. R. (1997). Signaling through focal adhesion kinase. BioEssays 19, 137-145.

Hirst, R., Horwitz, A., Buck, C. and Rohrschneider, L. (1986). Phosphorylation of the fibronectin receptor complex in cells transformed by oncogenes that encode tyrosine kinases. Proc. Natl. Acad. Sci. USA 83, 6470-6474.

Hungerford, J. E., Compton, M. T., Matter, M. L., Hoffstrom, B. G. and Otey, C. A. (1996). Inhibition of pp125FAK in cultured fibroblasts results in apoptosis. J. Cell Biol. 135, 1383-1390.

Hynes, R. O. (1992). Integrins: versatility, modulation, and signaling in cell adhesion. Cell 69, 11-25.

Ilic, D., Damsky, C. H. and Yamamoto, T. (1997). Focal adhesion kinase: at the crossroads of signal transduction. J Cell Sci 110, 401-407.

Jockusch, B. M., Bubeck, P., Giehl, K., Kroemker, M., Moschner, J., Rothkegel, M., Rudiger, M., Schluter, K., Stanke, G. and Winkler, J. (1995). The molecular architecture of focal adhesions. Annи. Rev. Cell Dev. Biol. 11, 379-416.

Johnson, R. P. and Craig, S. W. (1994). An intramolecular association between the head and tail domains of vinculin modulates talin binding. $J$. Biol. Chem. 269, 12611-12619.

Johnson, R. P. and Craig, S. W. (1995). F-actin binding site masked by the intramolecular association of vinculin head and tail domains. Nature $\mathbf{3 7 3}$, 261-264. 
Kaplan, K. B., Bibbins, K. B., Swedlow, J. R., Arnaud, M., Morgan, D. O. and Varmus, H. E. (1994). Association of the amino-terminal half of c-Src with focal adhesions alters their properties and is regulated by phosphorylation of tyrosine 527. EMBO J 13, 4745-4756.

Kaplan, K. B., Swedlow, J. R., Morgan, D. O. and Varmus, H. E. (1995). c-Src enhances the spreading of src-/- fibroblasts on fibronectin by a kinaseindependent mechanism. Genes Dev. 9, 1505-1517.

Katz, B. Z., Zamir, E., Bershadsky, A., Kam, Z., Yamada, K. M. and Geiger, B. (2000). Physical state of the extracellular matrix regulates the structure and molecular composition of cell-matrix adhesions. Mol. Biol. Cell 11, 1047-1060.

Kmiecik, T. E. and Shalloway, D. (1987). Activation and suppression of pp60 c-src transforming ability by mutation of its primary sites of tyrosine phosphorylation. Cell 49, 65-73.

Kries, T.E., Avnur, Z., Schlessinger, J. and Geiger, B. (1985). In: Molecular Biology of the Cytoskeleton (ed. G. Borisy, D. Cleveland and D. Murphy), pp. 45-57. Cold Spring Harbor: Cold Spring Harbor Laboratory Press.

Lin, S. and Lin, D.C. (1996).Mapping of actin, vinculin, and integrin binding domains suggests a direct role of tensin in actin-membrane association $\mathrm{Mol}$. Biol. Cell. 7, 389a

Liu, X., Marengere, L. E., Koch, C. A. and Pawson, T. (1993). The v-Src SH3 domain binds phosphatidylinositol 3'-kinase. Mol. Cell. Biol. 13, 5225-5232.

Lo, S. H., Janmey, P. A., Hartwig, J. H. and Chen, L. B. (1994). Interaction of tensin with actin and identification of its three distinct actin-binding domains. J. Cell Biol. 125, 1067-1075.

Maher, P. A., Pasquale, E. B., Wang, J. Y. and Singer, S. J. (1985). Phosphotyrosine-containing proteins are concentrated in focal adhesions and intercellular junctions in normal cells. Proc. Natl. Acad. Sci. USA 82, 6576-6580.

Matsumoto, K., Nakamura, T. and Kramer, R. H. (1994). Hepatocyte growth factor/scatter factor induces tyrosine phosphorylation of focal adhesion kinase (p125FAK) and promotes migration and invasion by oral squamous cell carcinoma cells. J. Biol. Chem. 269, 31807-31813.

Nada, S., Okada, M., MacAuley, A., Cooper, J. A. and Nakagawa, H. (1991). Cloning of a complementary DNA for a protein-tyrosine kinase that specifically phosphorylates a negative regulatory site of p60c-src. Nature 351, 69-72.

Nakanishi, O., Shibasaki, F., Hidaka, M., Homma, Y. and Takenawa, T. (1993). Phospholipase C-gamma 1 associates with viral and cellular src kinases. J. Biol. Chem. 268, 10754-10759.

Nigg, E. A., Sefton, B. M., Hunter, T., Walter, G. and Singer, S. J. (1982). Immunofluorescent localization of the transforming protein of Rous sarcoma virus with antibodies against a synthetic src peptide. Proc. Natl. Acad. Sci. USA 79, 5322-5326.

Ohmichi, M., Pang, L., Ribon, V., Gazit, A., Levitzki, A., Saltiel, A. R. (1993). The tyrosine kinase inhibitor tyrphostin blocks the cellular actions of nerve growth factor. Biochemistry 32, 4650-4658

Pankov, R. Cukierman, E., Katz, B. Z., Matsumoto, K., Lin, S., Hahn, C. and Yamada, K. M. (2000). Integrin dynamics and matrix assembly: tensindependent translocation of alpha(5)beta(1) integrins promotes early fibronectin fibrillogenesis. J. Cell Biol. 148, 1075-1090

Pasquale, E. B., Maher, P. A. and Singer, S. J. (1986). Talin is phosphorylated on tyrosine in chicken embryo fibroblasts transformed by Rous sarcoma virus. Proc. Natl. Acad. Sci. USA 83, 5507-5511.

Petch, L. A., Bockholt, S. M., Bouton, A., Parsons, J. T. and Burridge, K. (1995). Adhesion-induced tyrosine phosphorylation of the p130 src substrate. J. Cell Sci. 108, 1371-1379.

Rankin, S. and Rozengurt, E. (1994). Platelet-derived growth factor modulation of focal adhesion kinase (p125FAK) and paxillin tyrosine phosphorylation in Swiss 3T3 cells. Bell-shaped dose response and crosstalk with bombesin. J. Biol. Chem. 269, 704-710.

Reynolds, A. B., Kanner, S. B., Wang, H. C. and Parsons, J. T. (1989). Stable association of activated pp60src with two tyrosine-phosphorylated cellular proteins. Mol. Cell. Biol. 9, 3951-3958.

Richardson, A. and Parsons, T. (1996). A mechanism for regulation of the adhesion-associated proteintyrosine kinase pp125FAK. Nature 380, 538540.

Rohrschneider, L. R. (1980). Adhesion plaques of Rous sarcoma virustransformed cells contain the src gene product. Proc. Natl. Acad. Sci. USA 77, 3514-3518.

Rozengurt, E. (1995). Convergent signalling in the action of integrins, neuropeptides, growth factors and oncogenes. Cancer Surv. 24, 81-96.

Sakai, R., Iwamatsu, A., Hirano, N., Ogawa, S., Tanaka, T., Mano, H.,
Yazaki, Y. and Hirai, H. (1994). A novel signaling molecule, p130, forms stable complexes in vivo with v-Crk and v-Src in a tyrosine phosphorylationdependent manner. EMBO J. 13, 3748-3756.

Salgia, R., Pisick, E., Sattler, M., Li, J. L., Uemura, N., Wong, W. K. et al. (1996). p130CAS forms a signaling complex with the adapter protein CRKL in hematopoietic cells transformed by the BCR/ABL oncogene. J. Biol. Chem. 271, 25198-25203

Schaller, M. D., Borgman, C. A., Cobb, B. S., Vines, R. R., Reynolds, A. B. and Parsons, J. T. (1992). pp125FAK a structurally distinctive proteintyrosine kinase associated with focal adhesions. Proc. Natl. Acad. Sci. USA 89, 5192-5196.

Schaller, M. D., Hildebrand, J. D. and Parsons, J. T. (1999). Complex formation with focal adhesion kinase: A mechanism to regulate activity and subcellular localization of Src kinases. Mol. Biol. Cell 10, 3489-3505.

Schlaepfer, D. D., Broome, M. A. and Hunter, T. (1997). Fibronectinstimulated signaling from a focal adhesion kinase-c-Src complex: involvement of the Grb2, p130cas, and Nck adaptor proteins. Mol. Cell. Biol. 17, 1702-1713.

Schlaepfer, D. D. and Hunter, T. (1998). Integrin signalling and tyrosine phosphorylation: just the FAKs? Trends Cell Biol. 8, 151-157.

Schlaepfer, D. D., Jones, K. C. and Hunter, T. (1998). Multiple Grb2mediated integrin-stimulated signaling pathways to ERK2/mitogenactivated protein kinase: summation of both c-Src- and focal adhesion kinase-initiated tyrosine phosphorylation events. Mol. Cell. Biol. 18, 25712585.

Sieg, D. J., Hauck, C. R. and Schlaepfer, D. D. (1999). Required role of focal adhesion kinase (FAK) for integrin-stimulated cell migration. J. Cell Sci. 112, 2677-2691.

Smilenov, L. B,. Mikhailov, A., Pelham, R. J., Marcantonio, E. E and Gundersen, G. G. (1999) Focal adhesion motility revealed in stationary fibroblasts. Science 286, 1172-1174.

Tapley, P., Horwitz, A., Buck, C., Duggan, K. and Rohrschneider, L. (1989). Integrins isolated from Rous sarcoma virus-transformed chicken embryo fibroblasts. Oncogene 4, 325-333.

Tarone, G., Cirillo, D., Giancotti, F. G., Comoglio, P. M. and Marchisio, P. C. (1985). Rous sarcoma virus-transformed fibroblasts adhere primarily at discrete protrusions of the ventral membrane called podosomes. Exp. Cell Res. 159, 141-157.

Thomas, J. W., Ellis, B., Boerner, R. J., Knight, W. B., White, G. C., 2nd and Schaller, M. D. (1998). SH2- and SH3-mediated interactions between focal adhesion kinase and Src. J. Biol. Chem. 273, 577-583.

Thomas, S. M. and Brugge, J. S. (1997). Cellular functions regulated by Src family kinases. Annu. Rev. Cell Dev. Biol. 13, 513-609.

Towbin, H., Staehelin, T. and Gordon, J. (1992). Electrophoretic transfer of proteins from polyacrylamide gels to nitrocellulose sheets: procedure and some applications. 1979. Biotechnology 24, 145-149.

Turner, C. E. and Miller, J. T. (1994). Primary sequence of paxillin contains putative $\mathrm{SH} 2$ and $\mathrm{SH} 3$ domain binding motifs and multiple LIM domains: identification of a vinculin and pp125Fak-binding region. J. Cell Sci. 107, 1583-1591.

Volberg, T., Geiger, B., Dror, R. and Zick, Y. (1991). Modulation of intercellular adherens-type junctions and tyrosine phosphorylation of their components in RSV-transformed cultured chick lens cells. Cell Regul. 2, $105-120$.

Volberg, T., Zick, Y., Dror, R., Sabanay, I., Gilon, C., Levitzki, A. and Geiger, B. (1992). The effect of tyrosine-specific protein phosphorylation on the assembly of adherens-type junctions. EMBO J. 11, 1733-1742.

Wu, H., Reynolds, A. B., Kanner, S. B., Vines, R. R. and Parsons, J. T. (1991). Identification and characterization of a novel cytoskeletonassociated pp60src substrate. Mol. Cell. Biol. 11, 5113-5124.

Yamada, K. M. and Geiger, B. (1997). Molecular interactions in cell adhesion complexes. Curr. Opin. Cell Biol. 9, 76-85.

Zachary, I. (1997). Focal adhesion kinase. Int. J. Biochem. Cell Biol. 29, 929934.

Zamir, E., Katz, B. Z., Aota, S., Yamada, K. M., Geiger, B. and Kam, Z. (1999). Molecular diversity of cell-matrix adhesions. J. Cell Sci. 112, 16551669.

Zamir, E., Katz, M., Posen, Y., Erez, N., Yamada, K. M., Katz, B. Z., Lin, S., Lin, D. C., Bershadsky, A., Kam, Z. et al. (2000). Dynamics and segregation of cell-matrix adhesions in cultured fibroblasts. Nat. Cell Biol. 2, 191-196.

Zhao, J. H., Reiske, H. and Guan, J. L. (1998). Regulation of the cell cycle by focal adhesion kinase. J. Cell Biol. 143, 1997-2008. 